\title{
Microstructure and Tensile Properties of Fine-Grained Bulk Copper Fabricated by Thermomechanical Consolidation of Copper Nanopowder/Micron-Sized Powder Blend
}

\author{
Gyanendra Bhatta ${ }^{a}$, L. De Los Santos Valladares ${ }^{a, b, c, d *}$ (1), \\ A. Bustamante Domínguez ${ }^{c}$, N. O. Moreno ${ }^{e}$, C.H.W. Barnes ${ }^{d}$, Wen Chent, Deliang Zhang ${ }^{a, b}$ \\ ${ }^{a}$ Northeastern University, School of Materials Science and Engineering, 110819, Shenyang, People's \\ Republic of China. \\ ${ }^{b}$ Northeastern University, Key Laboratory of Data Analytics and Optimization for Smart Industry \\ (Ministry of Education), 110819, Shenyang, People's Republic of China. \\ 'Universidad Nacional Mayor de San Marcos, Facultad de Ciencias Físicas, Laboratorio de Cerámicos \\ y Nanomateriales, Ap. Postal 14-0149, Lima, Perú. \\ ${ }^{d}$ University of Cambridge, Department of Physics, Cavendish Laboratory, CB3 OHE, Cambridge, \\ United Kingdom. \\ ${ }^{e}$ Universidade Federal de Sergipe, Departamento de Física, 49100-000, São Cristóvão, SE, Brasil. \\ ${ }^{f}$ Laiwu Institute of Vocational Technology, Laiwu, Shandong Province, People's Republic of China.
}

Received: April 20, 2021; Revised: August 16, 2021; Accepted: September 5, 2021.

\begin{abstract}
Samples of fine structured $\mathrm{Cu}$ were fabricated by spark plasma sintering (SPS) of compacts of $\mathrm{Cu}$ nanopowder/micron-sized powder blend with a ratio of 3:7 by weight, and one of the SPSed samples was further processed by hot extrusion. The microstructures of the as-SPSed and the as-extruded samples and the tensile properties and fracture behavior of the as-extruded sample were studied. It was found that the microstructures of the samples consist of a concoction of ultrafine and coarse grains with high dislocation densities $\left(\sim 1015 \mathrm{~m}^{-2}\right)$ as a result of microstructural evolution during material processing. Some nanograins were oxidized to form $\mathrm{Cu}_{2} \mathrm{O}$ particles residing around the coarse grains. Extrusion of the SPSed sample increases its microhardness from $70 \mathrm{HV}$ to $90 \mathrm{HV}$. The electrical conductivity of the as-extruded sample reaches $87 \%$ international annealed copper standard (IACS), and its tensile properties are $200 \mathrm{MPa}$ for yield strength, $218 \mathrm{MPa}$ for ultimate tensile strength and $9 \%$ for elongation to fracture. The tensile test specimens from the as-extruded sample exhibit nearly ideal plastic deformation and undergo ductile fracture, suggesting that the fine-grained copper is a highly desirable material for high strength electrical conductors.
\end{abstract}

Keywords: Copper, fine grained microstructure, thermomechanical powder consolidation, powder metallurgy, mechanical properties.

\section{Introduction}

Over the past two decades, the fabrication of novel nanocrystalline $(\mathrm{NC})($ size $\leq 100 \mathrm{~nm})$ and ultrafine-grained (UFG) $($ size $\leq 1000 \mathrm{~nm})$ metallic materials have drawn close attention of the material research community, particularly focusing on the metals such as copper and nickel ${ }^{1,2}$. For industrial applications of NC/UFG materials, it is important to study both the pragmatic fabrication routes and the plausible mechanical performances of as-fabricated samples. Among the metals, pure copper $(\mathrm{Cu})$ has spurred a special attention for its potential applications in electronic and electrical engineering industries ${ }^{3,4}$.

The strength of UFG/NC Cu is two or threefold greater than that of their coarse grains counterparts ${ }^{5}$ due to the high density of grain boundaries (GBs) to strengthen them through boundary hardening ${ }^{6}$. Recently, it has been reported that the tensile ductility is accompanied (due to early strain accumulation) by diminished strain hardening capacity of such

*e-mail: 1d301@cam.ac.uk materials during plastic deformation ${ }^{7}$. However, in order to enhance the tensile ductility without compromising strength, various microstructure development strategies such as bimodal (coarse grain in NC/UFG matrix) microstructure ${ }^{8}$, gradients (nano-grain and twins) microstructure ${ }^{9}$, heterogeneous (nano grains and coarse grain) microstructure ${ }^{10}$ and nanocomposite (second phase nanoparticles in a NC/UFG Cu matrix) microstructure ${ }^{11-13}$ have been extensively studied. All of these strategies belong to either top-down approaches including equal channel angular pressing and rolling ${ }^{14,15}$, automotive roll bonding ${ }^{16,17}$ and high-pressure torsion ${ }^{18}$ or bottom-up approaches such as thermomechanical consolidation of NC/UFG powder into bulk materials ${ }^{19-21}$.

Among the various methods, fabrication of materials with bimodal microstructure by bottom-up approach is one of the prominent routes in which the UFG/NC grains exhibit enhanced tensile strength. Moreover, the coarse grains in the microstructure provide the strain hardening capacity to prolonging the ductility by maintaining the stable tensile 
deformation. Additionally, in heterogeneous and composite microstructure ${ }^{13}$, the strengthening mechanism such as grain boundary retardation by nanoparticle pinning (Zener pinning effect) ${ }^{22}$ and nanoparticle strengthening (Orowan's mechanism $)^{23}$ would come into an effect to drag the grain boundaries to ensure a slower grain growth rate. As a consequence, the materials retain a higher fraction of fine grains and improve their mechanical strength ${ }^{23,24}$.

In the present work, fine grained bulk copper samples were fabricated from a mixture of copper nanopowder and coarse grained and micrometer sized copper powder with a weight ratio of 30:70 and using a powder metallurgy (PM) route combining powder blending, spark plasma sintering (SPS) and hot extrusion (HE). The microstructures and microhardness of the as-SPSed and as-extruded samples and the tensile properties and fracture behavior of the asextruded samples were studied to elucidate microstructural evolution during processing and establish a correlation between the microstructure and mechanical properties of the fine-grained PM copper.

\section{Experimental Procedure}

An electrolytic commercial micrometer sized copper powder and a copper nanopowder were purchased from Shanghai ST-Nano Science and Technology Co. Ltd. The purity level, particle size and weight composition of the powders are listed in Table. 1. A mixture of the copper nanopowder and micrometer sized powder with a weight ratio of 30:70 was milled without using a process control agent (PCA) for 6 hours in a QM-3SP4 planetary ball mill (Nanjing Nanda instrument Ltd.) with a speed of $200 \mathrm{rpm}$. While milling, $5 \mathrm{~mm}$ diameter hardened stainless steel balls and a ball to powder weight ratio of 5:1 were used. The milled powder was then spark plasma sintered by using a HP D 25/4 furnace (FCT Systeme, Germany) in vacuum at temperature of $550{ }^{\circ} \mathrm{C}$ and compaction pressure of $50 \mathrm{MPa}$ with holding time of $5 \mathrm{~min}$. The heating rate was $100^{\circ} \mathrm{C} / \mathrm{min}$.

One of the as-SPSed samples was further processed by hot extrusion (HE) using a self-built multifunction thermomechanical powder consolidation equipment which combines a 200-ton hydraulic press (Huade Press Ltd, China), an induction heating equipment (Bamake Ltd, China) and a self-built glovebox for argon inert atmosphere protection. For the extrusion experiment, the SPSed sample was heated to $650{ }^{\circ} \mathrm{C}$ at an average heating rate of $100{ }^{\circ} \mathrm{C} \mathrm{min}$, held for $2 \mathrm{~min}$. and then extruded with an extrusion ratio of 9:1 to produce a cylindrical rod. The heating, holding, extrusion and cooling were performed under an argon inert atmosphere with an oxygen content of less than 200 ppm.

The density of both as-SPSed and as-extruded samples was measured based on the Archimedes principle by using an automatic ET-320 densimeter. An X-ray diffractometer (XRD)
(Rigaku Smart Lab) with $\mathrm{Cu}-\mathrm{K} \alpha$ radiation was employed for phase and crystallographic analysis. A step size of $0.02^{\circ}$ and scanning speed of $5^{\circ} / \mathrm{min}$ was maintained during XRD analysis. The microstructures of the samples were examined using optical microscopy (Axio lab A1, Zeiss), scanning electron microscopy (SEM, JSM-6510A) and transmission electron microscopy (TEM, JEM-2100F). The TEM specimens were prepared by double jet polishing methods using $30 \% \mathrm{HNO}_{3}$ in methanol. For energy back scattered diffraction (EBSD) analysis, a metallographic specimen from the as-extruded sample was prepared and polished using an electropolishing technique. Vickers microhardness measurements were performed on the polished surfaces of the metallography specimens at least ten times for each specimen, and the data were averaged to calculate the mean microhardness value. A load of 300 grams, indenting distance $0.2 \mathrm{~mm}$ and dwell time of $10 \mathrm{~s}$ were fixed during microhardness measurements. Dog-bone shaped tensile test specimens with a regular cross-section of $2 \times 3 \mathrm{~mm}^{2}$ and gauge length of $15 \mathrm{~mm}$ were cut from the as-extruded sample, and the tensile tests were performed at $5 \times 10^{-4} \mathrm{strain} / \mathrm{s}$. Four specimens were tested, and the mean value was calculated. Before tensile testing, the electrical resistance of the tensile test specimens was measured using a DC resistance meter (TH2525) based on four-probe methods. Linear fitting of the measured electrical resistance values with corresponding lengths was employed to minimize the effects of contact resistance and measured lengths on the measurement accuracy. The fracture surfaces of the tensile tested specimens were examined using SEM to analyze the fracture behavior of the as-extruded sample.

\section{Results and Discussions}

\subsection{Phase analysis by XRD}

Figure 1 is the indexed XRD patterns (in logarithmical scale) of the as- spark plasma sintered and as-extruded compact which showed $\{111\}\{200\}$ and $\{220\}$ peaks of face-centered cubic (FCC) $\mathrm{Cu}$. Pseudo-Voigt fit at full width half maximum (FWHM) and Williamson-Hall equation ${ }^{25}$ resulted in $1.17 \times 10^{15} \mathrm{~m}^{-2}$ and $2.1 \times 10^{15} \mathrm{~m}^{-2}$ dislocation density $\left(\rho=\frac{2 \sqrt{3}}{D b} \epsilon \mathrm{m}^{26}\right)$ for the as-SPSed and the as-hot extruded compact respectively. These results are higher than that of reported results of pure copper fabricated by equal channel angular rolling $\left(\sim 10^{14} \mathrm{~m}^{-2}\right)^{15}$ and copper matrix composite $\left(\sim 10^{13} \mathrm{~m}^{-2}\right)^{12}$ prepared by powder metallurgy. The high dislocation densities are predominantly attributed to the processing parameter selected in fabricating the compacts. Additional crystallographic parameters are shown in Table 2. The low lattice strain and high level of dislocation density of the hot extruded sample, as shown in Table 2, suggests that the crystalline lattices are remarkably stressed and corroborated with small crystallite size.

Table 1. Purity level, particle size and weight composition of precursor powder materials.

\begin{tabular}{cccc}
\hline Ingredient & Purity (\%) & Particle sizes & Weight percentage (\%) \\
\hline Cu nano-powder & 99.9 & $<100 \mathrm{~nm}$ & 30 \\
\hline Cu electrolytical powder & 99.9 & $-200 \operatorname{mesh}(<75 \mu m)$ & 70 \\
\hline
\end{tabular}


Table 2. Crystallographic parameters of as-SPSed and as-extruded copper samples from XRD analysis.

\begin{tabular}{cccc}
\hline Samples & Mean Crystallite size $(\mathbf{n m})$ & Lattice strain $(\mathbf{\%})$ & Dislocation density $\left(\mathbf{m}^{-2}\right)$ \\
\hline As-SPSed & 436 & 0.038 & $1.17 \times 10^{15}$ \\
\hline As-extruded & 118 & 0.022 & $2.1 \times 10^{15}$ \\
\hline
\end{tabular}

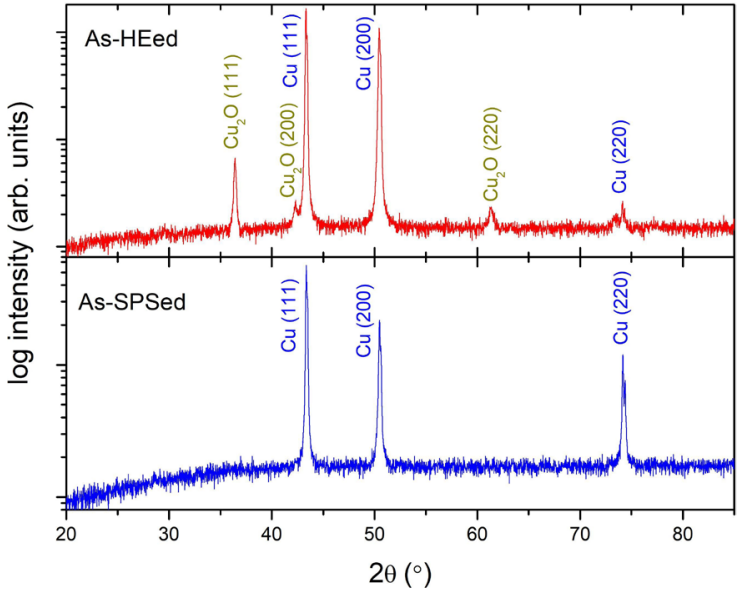

Figure 1. XRD profiles (in logarithmical scale) of as-SPSed and as-extruded samples.

The XRD plots in logarithmical scale show that the asSPSed sample presents the minor peaks of impurity, while the as-extruded sample demonstrates some minor peaks of Cuprite as shown in Figure 1. This suggests that hot extrusion enhances oxidation of $\mathrm{Cu}$ to $\mathrm{Cu}_{2} \mathrm{O}$ which might be due to the process and parameters used. Though, the result is consistent to the observed microstructure and EDS results below. Although, Tenorite $(\mathrm{CuO})$ - second oxide of $\mathrm{Cu}$ is probable oxide impurities, the XRD patterns do not detect Tenorite even in log scale plots. This is because its existence on $\mathrm{Cu}$ matrix according to enthalpy versus temperature diagram is unstable and an ultimate result is the formation of Cuprite following the oxide-reduction anti-dismutation reaction $(\mathrm{Cu}$ $\left.+\mathrm{CuO} \rightarrow \mathrm{Cu}_{2} \mathrm{O}\right)^{27}$. Such type of reaction is also observed in annealed copper powder at $750{ }^{\circ} \mathrm{C}$ under $\mathrm{H}_{2}{ }^{28}$. Being similar intensity ratios of 2.17 and 2.30 for $\{111\} /\{200\}$ and $\{200\} /\{220\}$ peaks in both samples showed absence of shear bands in microstructure. Additionally, the as-extruded sample consists of $4.5 \mathrm{wt} \%(6.5 \mathrm{vol}, \%)$ of $\mathrm{Cu}_{2} \mathrm{O}$ particles with the balance being $\mathrm{Cu}$ matrix, as calculated from the XRD result. The crystallite size of $\mathrm{Cu}_{2} \mathrm{O}$ particles was calculated to be $\sim 40 \mathrm{~nm}$ from its first two peaks and using the Scherrer's equation ${ }^{29}$ :

$D=\frac{0.916 \lambda}{\beta_{h k l} \cos \theta_{h k l}}$

Where $D$ is the average size of the crystallite, $\lambda$ Is the wavelength of the X-ray beam $\left(\lambda_{\mathrm{Cu}-\mathrm{Ka}}=0.154184 \mathrm{~nm}\right), \Theta_{H k l}$ is Bragg's angle and $\beta_{H k l}$ is the widening of the peak of diffraction (in radians), which can be determined by measuring the full width at the half maximum (FWHM) from the main reflections (main $h k l$ ) for each phase.

\subsection{Density and electrical conductivity}

The average density of as-SPSed and as-extruded samples were found to be $8.35 \mathrm{~g} / \mathrm{cm}^{3}$ and $8.21 \mathrm{~g} / \mathrm{cm}^{3}$ respectively

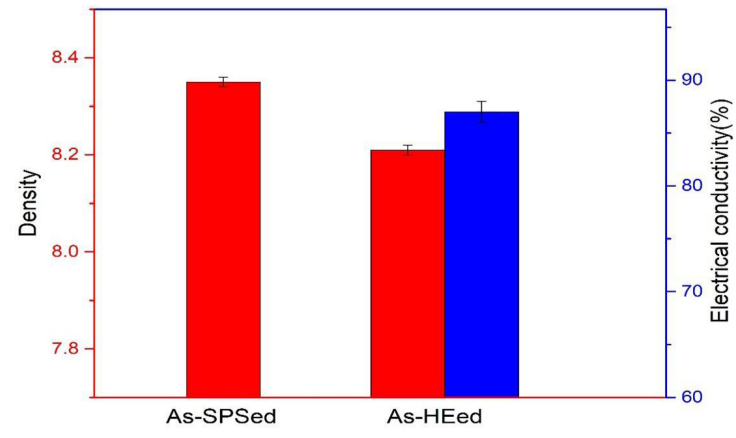

Figure 2. The density and the electrical conductivity of the compacts.

(see Figure 2). The results seemed quite lower than that of theoretical density $\left(8.96 \mathrm{~g} / \mathrm{cm}^{3}\right)$ of pure copper which is partly attributed to micropores. Additionally, the light $\mathrm{Cu}_{2} \mathrm{O}$ with a density of $6 \mathrm{~g} / \mathrm{cm}^{3}$ in microstructure is responsible to achieve slightly lower density results. The reason for the slightly lower density of the hot extruded compacts is the cubical expansion of entrapped gases inside the pores and the increased contents of lighter $\mathrm{Cu}$ oxides. The electrical conductivity measurement of the as hot extruded sample showed $87 \%$ of IACS which is the resemblance to the result of pure copper compacts ( $~ 88 \%$ IACS $)$ prepared by selective laser melting $(\mathrm{SLM})^{30}$ and higher than $\mathrm{Cu}-\mathrm{NbC}$ composite alloy (70-85\% IACS) prepared by powder metallurgy ${ }^{11}$. The lower results of electrical conductivity are attributed to $\mathrm{Cu}_{2} \mathrm{O}$ which is a P-type semiconductor with the bulk direct band gap in the range of $2-2.17 \mathrm{eV}^{28,31}$ and plenty of dislocations to scattering the conductive electrons.

\subsection{Microstructure analysis}

Figures 3(a) and (b) show the light microscopy images of the as-SPSed and as-extruded copper samples respectively. Figure 3(a) demonstrated that the microstructure of as SPSed sample consists of a mixture of coarse grains and ultrafine grains. A few of them are very large, disoriented with ovalshaped structure suggesting that the coarse grains do not prefer to grow in a fixed direction. The large coarse grain has length up to $35 \mu \mathrm{m}$ along the longitudes. These large coarse grains provide bounty of space for dislocations activities in tension. For balanced mechanical performances, the coarse grain offers enormous space for strain hardening and the UFG grains restrict intra-granular dislocations via; grain boundary hardening ${ }^{8,10,11}$. In addition, some of the nanograins are oxidized instead of growing during sintering leading to second phase which could be seen as black particles at and around the coarse grain boundaries in the microstructure. As shown in Figure 3(b), the microstructure of as-hot extruded compacts seemed slightly refined grains due to internal stress in hot extrusion step and obscure grain boundaries due to high dislocations and oxidized second phase. Additionally, 
EBSD technique is used to analyze further microstructure of the as-extruded sample.

Figures 4(a) and (b) show the SEM backscattered electron micrographs (BEI) of the as-SPSed and as-extruded samples, respectively. As shown in Figure 4(a), the thick grain boundaries in the as-SPSed samples might be due to oxidized nanograins at the boundaries between the coarse grains in line to the OM observation. This may also be the effect of grain boundary on the oxidation behavior of $\mathrm{Cu}$. Of course, the grain boundaries are more open space than
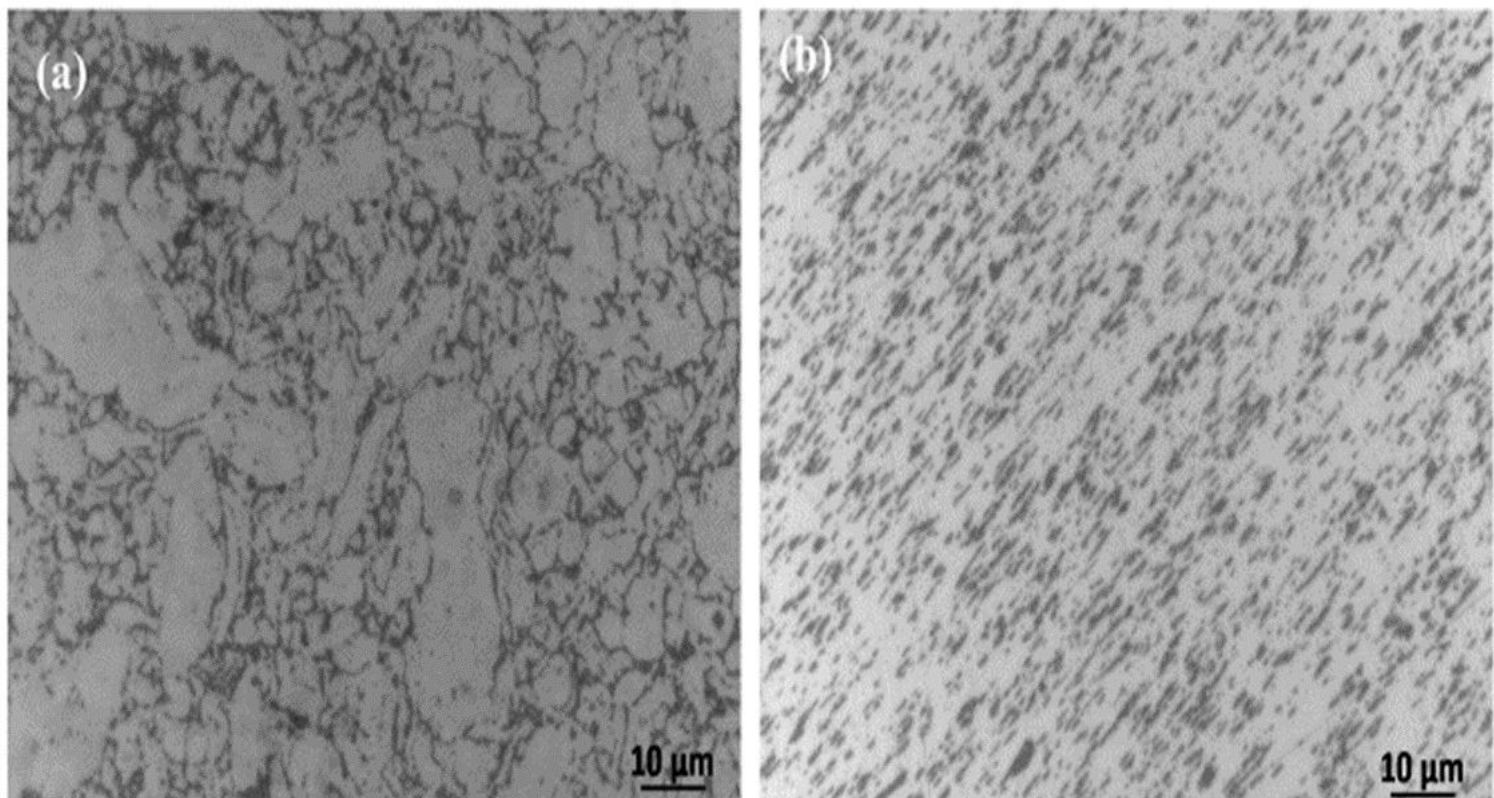

Figure 3. Light microscopy micrographs (a) as-SPSed and (b) as-extruded samples respectively.
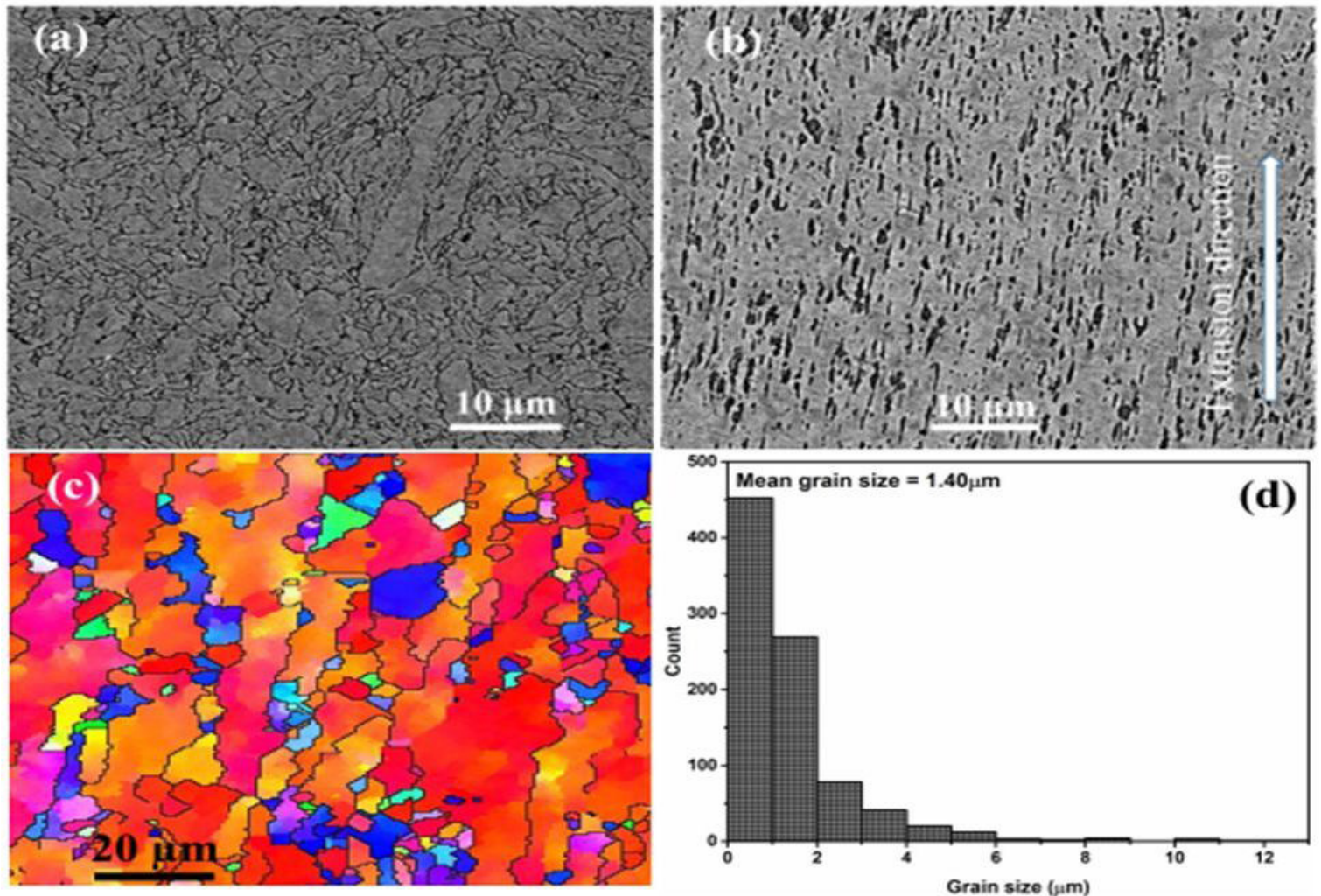

Figure 4. (a) and (b) BEI images of the as-SPSed and as-extruded samples, (c) EBSD inverse pole figure (IPF) contrast map and (d) the grain size distribution of as-extruded sample. 
the matrix and may become easier to be oxidized. Though, the in-depth role of grain boundary on the oxidation of copper is in reference $\left[{ }^{32}\right]$ which suggests that the activation energy beyond $100 \mathrm{~kJ} / \mathrm{mol}$ is correlated to vacancy mediated diffusion of copper atoms leading to boundary oxidations. As could be seen in Figure 4(b), the grain boundaries of the as-extruded sample are still unclear. However, the matrix microstructure is deformed along the extrusion direction as shown by the arrow in the micrograph. Additionally, the harder brittle oxides elongated and some of them split up due to mechanical stress during extrusion. Also, some micropores were observed in the SEI images (not shown). It is previously claimed that well homogenized powder is sintered reasonably leading to low percentage of micropores around the powder particle junctions ${ }^{33}$. The EDS test results of the as-hot extruded sample demonstrate that the oxygen content of the as-extruded sample is in agreement with the $\mathrm{XRD}$ results. From the EDS analysis results, the black regions and $\mathrm{Cu}$ matrix contain $8.8 \mathrm{wt} \%$ (27.59 at $\%$ ) and $0.06 \mathrm{wt} \%$ (0.26 at $\%)$ of oxygen respectively.

The EBSD coloring micrograph of the as-extruded sample is shown in Figure 4(c) which demonstrates the elongated matrix grains along the extrusion direction in consistent result of BEI micrographs. Additionally, the grain boundaries of coarse grains are not smooth and some fine grains are trapped around these curved boundaries. Moreover, some fine grains which look like recrystallized grains are distributed at the grain triple junctions. Interestingly, few fine grains are seen inside the coarse grains as well. Figure 4(d) shows the grain size distribution with mean size of $1.40 \mu \mathrm{m}$. Furthermore, most of the grains have sizes below $1 \mu \mathrm{m}$ and some are in UFG regime. In addition, the coarse grains varied from 1 to $11 \mu \mathrm{m}$ with mean size of $1.67 \mu \mathrm{m}$ and ultrafine grains varied from 350 to $1000 \mathrm{~nm}$ with mean size of $303 \mathrm{~nm}$ respectively.
Very few counts of grains have large sizes, indicating that significant grain growth is suppressed during extrusion.

It is already claimed that the low stacking fault materials such as copper undergo partial recrystallization leading to bimodal microstructure due to heat in severe deformation ${ }^{34}$. In contrast, the UFG grains are due to the growth of unoxidized nano grains. However, grain growth could be controlled by adjusting a fast heating rate that would facilitate surface diffusion instead of mass transport and a short holding period for limiting growth time ${ }^{35}$. Moreover, grain boundary dragging by second phase, impurities and solute (Kinetic approach) and particle segregating from the boundaries (thermodynamic approach) are additional strategies to control growth $^{36}$. Thus, $\mathrm{Cu}_{2} \mathrm{O}$ particles at the grain boundaries might drag the boundary migration of some nano grains in growth process and rendered them in ultrafine regime as shown in grain size distribution graph.

The TEM micrographs in Figure 5 showed some dislocations (Figure 5(a)) in the SPSed sample which is consistent with $\mathrm{XRD}$ result, and the microstructure of as-extruded sample has several nanograins (Figure 5(b)) as shown in arrowhead. This is consistent to the pure commercial copper compact prepared by accumulative roll bonding $\left[{ }^{16}\right]$.

\subsection{Mechanical properties and fracture behavior}

The representatives tensile engineering stress-strain curves of four tested specimens cut from the as-extruded sample are shown in Figure 6(a). They show that the material exhibits nearly ideal plastic flow behaviors similar to the material flow behavior demonstrated by NC/UFG copper previously reported ${ }^{37}$. The steady plastic flow of the materials might be due to dynamic balance between dislocation generation in the deformation process and dislocation annihilation during tensile testing. Additionally, the sample exhibits rapid strain hardening in the initial stage of plastic deformation after
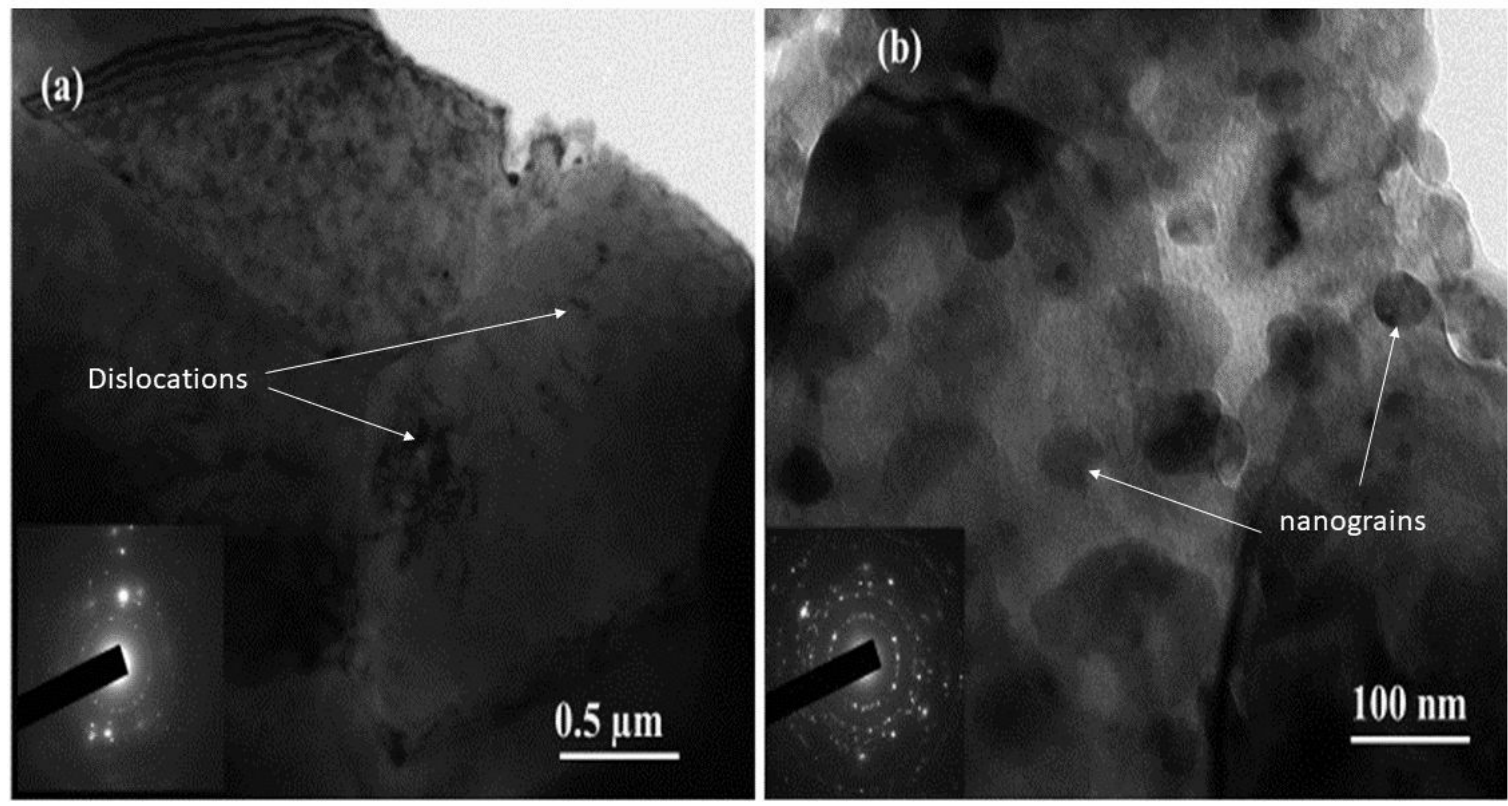

Figure 5. TEM bright field images (a) as-SPSed sample and (b) as-extruded sample. 
yielding which can be attributed to the high initial dislocation density $^{38}$ similar to other metallic materials fabricated by severe plastic deformation and ball milling ${ }^{39}$. The measured average yield strength $(200 \mathrm{MPa})$ and ultimate tensile strength $(218 \mathrm{MPa})$ are higher than those $(\mathrm{YS}=78 \sim 87 \mathrm{MPa}$, $\mathrm{UTS}=158 \sim 177 \mathrm{MPa})$ of coarse grained copper fabricated by selective electron beam melting $(\mathrm{SEBM})^{40}$. The difference between the YS and UTS of the ax-extruded $\mathrm{Cu}$ sample is due to the UFG grains in the microstructure of as-extruded $\mathrm{Cu}$ sample. However, the observed elongation to fracture of the extruded $\mathrm{Cu}$ sample $(\sim 9 \%)$ is lower than that of SEBMed Cu sample $(\sim 14 \%)$.

The Vickers microhardness of both as-SPSed and asHEed compacts are shown in Figure 6(b) with an average result of $70 \pm 2 \mathrm{HV}$ and $90 \pm 2 \mathrm{HV}$, respectively. Both samples exhibit approximately $48 \%$ and $90 \%$ more microhardness than coarse grained $\mathrm{Cu}$ sample annealed at $600^{\circ} \mathrm{C}$ for 2 hours $(47.3 \mathrm{HV})^{14}$ and the $\mathrm{Cu}$ sample pure copper processed via
SEBM $(46-48 \mathrm{HV})^{40}$. In addition, the microhardness of the as-SPSed sample is similar to the microhardness of UFG Cu annealed at $673 \mathrm{~K}$ for 3 hours ( $69 \mathrm{HV}$ ), while the microhardness of the as-extruded sample is clearly higher than that UFG-Cu prepared by ECAP followed by annealing at $573 \mathrm{~K}$ for 10 hours $(83.4 \mathrm{HV})^{14}$. The consistent and repeatable microhardness results as could be seen in Figure 6(b) demonstrated the microstructural isotropy along the surface. The enhanced microhardness of the as-extruded sample as compared with that of as-SPSed sample is apparently colligated with the change in microstructural features.

The strengthening of as- extruded sample is attributed by grain boundary hardening and dislocation strengthening. The grain boundary hardening can be ascribed by the well-known Hall-Petch equation $\Delta \sigma_{\mathrm{y}}=\mathrm{KHPD}^{-1 / 225}$. Where $\sigma_{\mathrm{y}}$ is the yield stress and $\mathrm{KHP}=0.11 \mathrm{MPam}^{-1 / 2}$ material constant. The calculated grain boundary strengthening contribution to the strength is $\sim 93 \mathrm{MPa}$. The dislocations strengthening contribution is
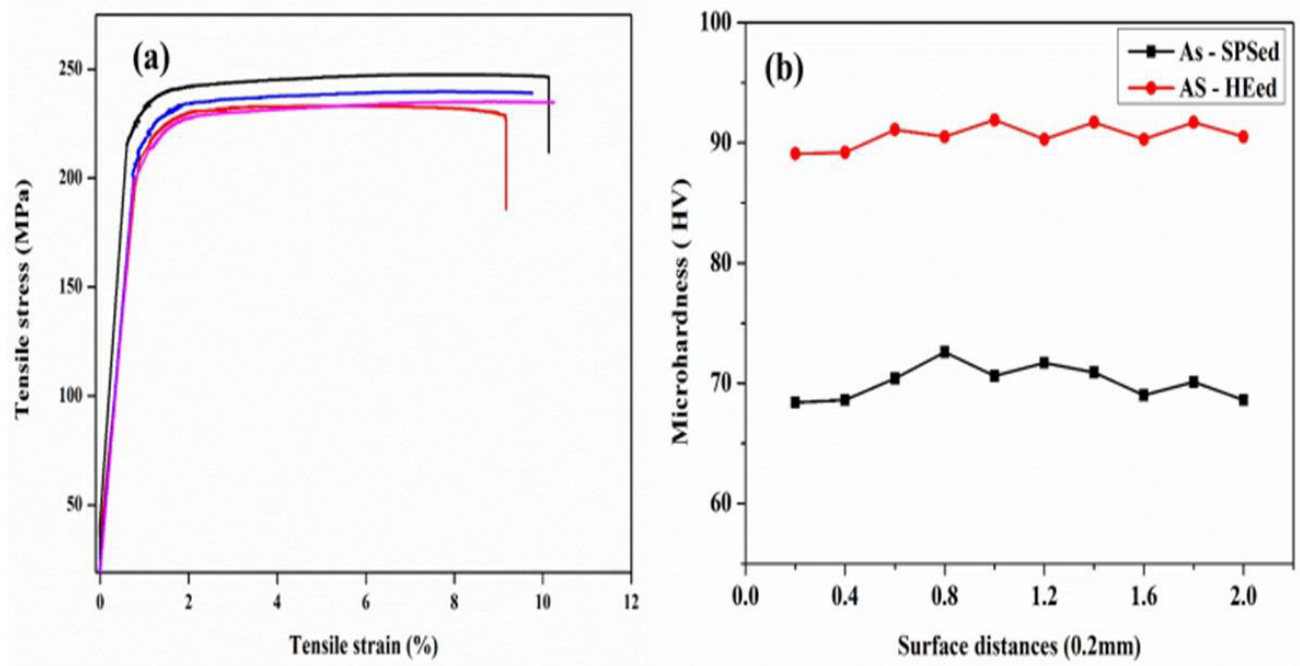

Figure 6. (a) Tensile stress-strain curves of as-extruded sample and (b) Vickers microhardness profile over 02 mm surface distances.
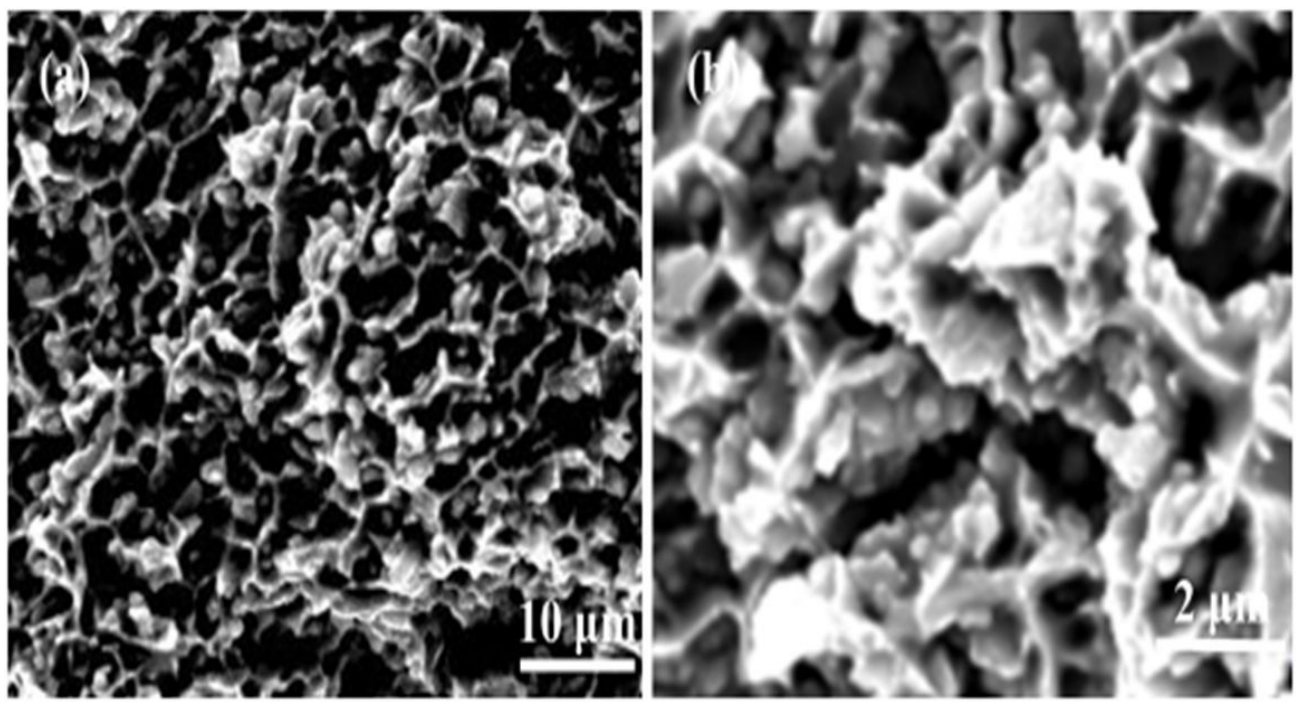

Figure 7. Fracture morphology of as-extruded sample (a) at lower magnification, (b) at higher magnification. 
described by Taylor's equation $\Delta \sigma_{\text {dis }}=\mathrm{M}^{\alpha} \mathrm{Gb}^{\rho} 0.5^{41}$, where Taylor's $(\mathrm{M})=3.06$, strength coefficient of dislocation $(\alpha)=0.2$, Shear modulus $(\mathrm{G})=47.7 \mathrm{MPa}$ and Burger's vector (B) $=0.256 \mathrm{~nm}$ and the calculated results $\sim 109 \mathrm{MPa}$. For pure $\mathrm{Cu}$, the material contribution $\left(\sigma_{0}\right)$ is quite small and is the order of $5 \mathrm{MPa}$. Therefore, the strength is described by the sum of individual contributors as: $\sigma=\sigma_{0}+\Delta \sigma_{\mathrm{gb}}+\Delta \sigma_{\mathrm{dis}}$. The calculated result is $207 \mathrm{MPa}$ slightly more than the experimental result $(\sim 200 \mathrm{MPa})$.

The SEM micrographs of fractured surfaces of the tensile tested specimens cut from the as-extruded samples are shown in Figure 7. The fracture morphology consists of dimples of sizes varying from small to large and shapes varying from round and shallow to irregular and deep. The dimples are interconnected by soft ductile ligaments indicating ductile fracture. The observed fracture surface is partly resembling to the fracture morphology of UFG copper with a bimodal microstructure. It could also be seen in Figure 7(b) that the localized thick, deep and round dimples suggested the appreciable local plasticity retained in the materials. The tortuous crack propagation (not shown) is, in contrast, to crack profile as demonstrated by pure ultrafine grained copper, low density nano twin copper and high density nano twin copper ${ }^{42}$. The tortuosity in the crack propagation is attributed to bimodal microstructure in which large grains appearing on crack path leads to crack ridges ${ }^{43}$. Moreover, the brittle cuprite facilitated to achieve short stable intercrystalline crack propagation in between crack ridges.

\section{Conclusions}

Fine grained bulk copper samples with grain sizes ranging from 0.3 to $11.195 \mu \mathrm{m}$, were successfully fabricated by SPS of compacts of $\mathrm{Cu}$ nanopowder/micron-sized powder blend with a weight ratio of 30:70 followed by hot extrusion of the SPSed sample. Trivial oxidation of $\mathrm{Cu}$ nanograins occurs during hot extrusion, leading to the formation of $\mathrm{Cu}_{2} \mathrm{O}$ particles around $\mathrm{Cu}$ coarse grains. The microstructural changes of the sample during extrusion cause a significant increase of its microhardness from 70 to $90 \mathrm{HV}$. The as-extruded $\mathrm{Cu}$ sample exhibits a reasonable high YS $(200 \mathrm{MPa})$ and UTS $(218 \mathrm{MPa})$ thanks to grain boundary strengthening and dislocation hardening and good tensile ductility (elongation to fracture: $9 \%$ ) which can be attributed to the activities of dislocations inside the coarse grains in fine grain microstructure with a large range of grain sizes. The as-extruded sample also has a high electrical conductivity ( $87 \%$ IACS), and demonstrates ideal plastic deformation and ductile fracture behaviors which are highly desirable for applications requiring high electrical conductivity and good mechanical performance.

\section{Acknowledgments}

G. Bhatta and D. Zhang thank the financial support from China Scholarship Council (CSC) (grant nos. 2017GXZ026346) and the "Xing Liao Talent Plan" of Liaoning Province, China (Project No. XLYC1802080) to the work in China. The work in Peru has been supported by the Incorporación de Investigadores Program from the CONCYTEC - FONDECYT - UNMSM (Contract No. 12 -2019 - FONDECYT - BM - INC. INV.).

\section{References}

1. Asaro RJ, Suresh S. Mechanistic models for the activation volume and rate sensitivity in metals with nanocrystalline grains and nano-scale twins. Acta Mater. 2005;53(12):3369-82.

2. Zhang ZH, Wang FC, Lee SK, Liu Y, Cheng JW, Liang Y. Microstructure characteristic, mechanical properties and sintering mechanism of nanocrystalline copper obtained by SPS process. Mater Sci Eng A. 2009;523(1-2):134-8.

3. Chen W, Luo G, Li M, Shen Q, Wang C, Zhang L. Effect of $2,2^{\prime}$-dipyridyl on the plating rate, microstructure and performance of copper-coated tungsten composite powders prepared using electroless plating. Appl Surf Sci. 2014;301:85-90.

4. Zhilyaev AP, Shakhova I, Belyakov A, Kaibyshev R, Langdon TG. Wear resistance and electroconductivity in copper processed by severe plastic deformation. Wear. 2013;305(1-2):89-99.

5. Koch CC, Morris DG, Lu K, Inoue A. Ductility of nanostructured materials. MRS Bull. 2013;24(2):54-8.

6. Hansen N. Hall-Petch relation and boundary strengthening. Scr Mater. 2004;51(8):801-6.

7. Ma E. Instabilities and ductility of nanocrystalline and ultrafinegrained metals. Scr Mater. 2003;49(7):663-8.

8. Wang W, Zeng W, Li C, Liang J, Zhang D. Microstructure and mechanical properties of ultrafine grained $\mathrm{Cu}-0.8 \mathrm{wt} \% \mathrm{C}$ alloy with a bimodal microstructure produced by powder metallurgy techniques. Mater Sci Eng A. 2018;712:214-22.

9. Wang G, Li G, Zhao L, Lian J, Jiang Z, Jiang Q. The origin of the ultrahigh strength and good ductility in nanotwinned copper. Mater Sci Eng A. 2010;527(16-17):4270-4.

10. Chen W, You ZS, Tao NR, Jin ZH, Lu L. Mechanically-induced grain coarsening in gradient nano-grained copper. Acta Mater. 2017;125:255-64.

11. Zeng W, Xie J, Zhou D, Fu Z, Zhang D, Lavernia EJ. Bulk $\mathrm{Cu}-\mathrm{NbC}$ nanocomposites with high strength and high electrical conductivity. J Alloys Compd. 2018;745:55-62.

12. Zhou D, Zeng W, Zhang D. A feasible ultrafine grained $\mathrm{Cu}$ matrix composite microstructure for achieving high strength and high electrical conductivity. J Alloys Compd. 2016;682:590-3.

13. Zhou D, Wang X, Muránsky O, Wang X, Xie Y, Yang C, et al. Heterogeneous microstructure of an $\mathrm{Al} 2 \mathrm{O} 3$ dispersion strengthened $\mathrm{Cu}$ by spark plasma sintering and extrusion and its effect on tensile properties and electrical conductivity. Mater Sci Eng A. 2018;730:328-35.

14. Suo T, Li Y, Xie K, Zhao F, Zhang K, Liu Y. The effect of temperature on mechanical behavior of ultrafine-grained copper by equal channel angular pressing. Mater Sci Eng A. 2010;527(21-22):5766-72.

15. Kvackaj T, Kovacova A, Kocisko R, Bidulska J, LityńskaDobrzyńska L, Jenei P, et al. Microstructure evolution and mechanical performance of copper processed by equal channel angular rolling. Mater Charact. 2017;134:246-52.

16. Fattah-Alhosseini A, Imantalab O, Mazaheri Y, Keshavarz MK. Microstructural evolution, mechanical properties, and strain hardening behavior of ultrafine grained commercial pure copper during the accumulative roll bonding process. Mater Sci Eng A. 2016;650:8-14.

17. Hosseini SA, Manesh HD. High-strength, high-conductivity ultra-fine grains commercial pure copper produced by ARB process. Mater Des. 2009;30(8):2911-8.

18. Shi S, Zhang Z, Wang X, Zhou G, Xie G, Wang D, et al. Microstructure evolution and enhanced mechanical properties in SUS316LN steel processed by high pressure torsion at room temperature. Mater Sci Eng A. 2018;711:476-83.

19. Srinivasarao B, Oh-ishi K, Ohkubo T, Hono K. Bimodally grained high-strength Fe fabricated by mechanical alloying and spark plasma sintering. Acta Mater. 2009;57(11):3277-86.

20. Oh-ishi K, Zhang HW, Ohkubo T, Hono K. Microstructure characterization of bulk nanocrystalline $\mathrm{Fe}-0.8 \mathrm{C}$ alloy produced 
by mechanical milling and spark plasma sintering. Mater Sci Eng A. 2007;456(1-2):20-7.

21. Srinivasarao B, Oh-ishi K, Ohkubo T, Mukai T, Hono K. Synthesis of high-strength bimodally grained iron by mechanical alloying and spark plasma sintering. Scr Mater. 2008;58(9):759-62.

22. Koju RK, Darling KA, Kecskes LJ, Mishin Y. Zener pinning of grain boundaries and structural stability of immiscible alloys. JOM. 2016;68(6):1596-604.

23. Akbarpour MR, Salahi E, Hesari FA, Kim HS, Simchi A. Effect of nanoparticle content on the microstructural and mechanical properties of nano-SiC dispersed bulk ultrafine-grained $\mathrm{Cu}$ matrix composites. Mater Des. 2013;52:881-887.

24. Akbarpour MR, Salahi E, Hesari FA, Yoon EY, Kim HS, Simchi A. Microstructural development and mechanical properties of nanostructured copper reinforced with $\mathrm{SiC}$ nanoparticles. Mater Sci Eng A. 2013;568:33-9. https://doi.org/https://doi. org/10.1016/j.msea.2013.01.010

25. Kato M. Hall-Petch relationship and dislocation model for deformation of ultrafine-grained and nanocrystalline metals. Mater Trans. 2014;55(1):19-24.

26. Williamson GK, Smallman RE 3rd. Dislocation densities in some annealed and cold-worked metals from measurements on the X-ray debye-scherrer spectrum. Philos Mag Lett. 1956;1(1):34-46.

27. Zhu Y, Mimura K, Isshiki MJMt. Oxidation mechanism of copper at 623-1073 K. Mater Trans. 2002;43(9):2173-6.

28. Monnier J, Champion Y, Perrière L, Villeroy B, Godart C. Spark plasma sintering and hydrogen pre-annealing of copper nanopowder. Mater Sci Eng A. 2015;621:61-7.

29. Martinez MAR, Felix LL, Valladares LS, Dominguez AB, Coaquira JAH, Alvarado JR, et al. Characterization of copper microelectrodes following a homade lithography technique and gold electroless deposition. Materia. 2016;21(1):252-259. https://doi.org/10.1590/S1517-707620160001.0023

30. Jadhav SD, Dadbakhsh S, Goossens L, Kruth JP, Van Humbeeck $\mathrm{J}$, Vanmeensel K. Influence of selective laser melting process parameters on texture evolution in pure copper. J Mater Process Technol. 2019;270:47-58.

31. Valladares LS, Salinas DH, Dominguez AB, Najarro DA, Khondaker SI, Mitrelias T, et al. Crystallization and electrical resistivity of $\mathrm{Cu}_{2} \mathrm{O}$ and $\mathrm{CuO}$ obtained by thermal oxidation of $\mathrm{Cu}$ thin films on $\mathrm{SiO}_{2} / \mathrm{Si}$ substrates. Thin Solid Films. 2012;520:6368-74.

32. Maack B, Nilius N. In-situ optical view onto copper oxidation - role of reactive interfaces and self-heating. Corros Sci. 2019; 159:108112.

33. Rabiei A, O'Neill AT. A study on processing of a composite metal foam via casting. Mater Sci Eng A. 2005;404(1-2):159-64.

34. Lugo N, Llorca N, Cabrera JM, Horita Z. Microstructures and mechanical properties of pure copper deformed severely by equal-channel angular pressing and high pressure torsion. Mater Sci Eng A. 2008;477(1-2):366-71.

35. Mamedov V. Spark plasma sintering as advanced PM sintering method. Powder Metall. 2013;45(4):322-8.

36. Koch CC. Structural nanocrystalline materials: an overview. J Mater Sci. 2007;42(5):1403-14.

37. Guduru RK, Murty KL, Youssef KM, Scattergood RO, Koch CC. Mechanical behavior of nanocrystalline copper. Mater Sci Eng A. 2007;463(1-2):14-21.

38. Hodge AM, Wang YM, Barbee TW. Mechanical deformation of high-purity sputter-deposited nano-twinned copper. Scr Mater. 2008;59(2):163-6.

39. Cheng S, Ma E, Wang Y, Kecskes L, Youssef K, Koch C, et al. Tensile properties of in situ consolidated nanocrystalline $\mathrm{Cu}$. Acta Mater. 2005;53(5):1521-33.

40. Guschlbauer R, Momeni S, Osmanlic F, Körner C. Process development of $99.95 \%$ pure copper processed via selective electron beam melting and its mechanical and physical properties. Mater Charact. 2018;143:163-70.

41. Zhou D, Zhang D, Kong C, Munroe P, Torrens R. Grain and nanoparticle coarsening of an ultrafine structure $\mathrm{Cu}-5 \mathrm{vol} . \% \mathrm{Al} 2 \mathrm{O} 3$ nanocomposite during isochronal annealing. J Alloys Compd. 2015;642:83-91.

42. Singh A, Tang L, Dao M, Lu L, Suresh S. Fracture toughness and fatigue crack growth characteristics of nanotwinned copper. Acta Mater. 2011;59(6):2437-46.

43. Hanlon T, Tabachnikova E, Suresh S. Fatigue behavior of nanocrystalline metals and alloys. Int J Fatigue. 2005;27(1012):1147-58. 